\title{
Triangulation Approaches in Finance Research
}

\author{
N.J.T.K.G.P.Dewasiri ${ }^{1}$, Dr. Y.K. Weerakoon Banda ${ }^{2}$ and Dr. A.A. Azeez ${ }^{3}$ \\ ${ }^{1}$ Faculty of Graduate Studies, University of Colombo. \\ 2 Department of Finance, University of Sri Jayewardenepura. \\ ${ }^{3}$ Head, Department of Finance, University of Colombo.
}

\begin{abstract}
The purpose of this study is to critically and comprehensively review the ways and means of using triangulation in finance research to overcome the current drawbacks arisen from a single approach. Employing systematic literature review method, the findings divulged that the finance based research studies on quantitative methods, behavioural and proxy variables should be further validated through triangulation approaches, thereby increasing the validity, completeness, confirmation, and confidence over findings, minimizing the inherent weaknesses of single-method approaches, and avoiding contradictions over explanations. This study is the first comprehensive review of the uses of triangulation in finance research and it demonstrates how, why and under what circumstances can triangulation be meaningfully integrated and implemented to provide a deeper and comprehensive understanding of finance phenomena.
\end{abstract}

Key Words: Triangulation approach; validity; completeness; confirmation; finance research; proxy variables

\section{Introduction}

Quantitative research methodology has been one of most popular approaches to finance research over the past thirty years. Baker et al. (2011) noted that empirical studies in finance tend to rely on a large number of financial observations, resulting in robust statistical power and analysis if crosssectional variation, and identify the fact that "researchers have limited ability 
to deal with non-quantifiable issues" as major problem in the discipline. Dewasiri and Weerakoon (2016) recently argued that most of finance studies $(68 \%)$ in the last decades have used proxy variables in behavioural models. For instance, Jiraporn et al. (2015) investigated the relationship between managerial ability (measured through proxies) and dividend policy. Wang et al. (2016) tested the catering theory of dividends by applying a proxy for investor's demand or preference. We argue that real behaviours may be very distinct from what is captured by proxy explanations, and hence further investigation is required to achieve more consensual accounts of financial behaviour.

Quantitative approaches have been predominant in recent finance research, and as a result few scholars have highlighted the importance of supplementary approaches. For instance, Burton (2007) identified the importance of qualitative approaches in finance, highlighting early financial studies (Lintner, 1956) based on qualitative data.

Turner et al. (2013) conducted a study based on secondary data on traded companies in the London Stock Market between 1825 and 1870 to investigate the "dividend puzzle" (namely, the puzzle of why companies pay dividends). However, it remains debatable whether their results derived from the use of proxy variables are valid in explaining the behavioural decision to pay dividends. Moreover, investigation of dividend puzzle is still remaining as a controversy issue in finance even though it is investigated for decades through quantitative approaches. As stated by Frankfurter et al. (2002), it is unable to understand the dividend puzzle simply analysing the secondary (market) data. As Bruner (2002) stated "The task must be to look for patterns of confirmation across approaches and studies much like one sees an image in a mosaic of stones.' Shih (1998) emphasized that confirmation of 
findings as the common objective of triangulation in a quantitatively weighted research whereas Green (2007) epitomized that completeness and cohesiveness as the rational for utilization of triangulation approach in a qualitatively bounded research. Here, we argue that confirmation of the findings of two different approaches or methodologies pave the way towards a completeness, cohesiveness, validity and generalizability of the findings than a single methodology in finance research as supported by Baker et al. (2011). Accordingly, this study will contribute to the finance research phenomenon by filling this methodological gap emphasizing the ways and means of using triangulation as an alternative approach in finance research in order to minimize inherent weaknesses of a single approach. We also point out that employing proxy variables hinders the completeness and validity of financial studies.

Triangulation has been recognized for some time as a potential solution to this issue and it could be identified as a powerful approach that facilitates confirmation and validation of findings through two or more methods / sources in a single study. In particular, Denzin (1970) argued that the more intensive the use of triangulation, the greater the confidence in observed findings. Decrop (1999) identified triangulation as a state of mind where creativity is required from researchers, and urged them to generalize the use of triangulation as a way of obtaining sound and valid results. After Denzin (1970), triangulation is becoming a widely accepted approach as a way to enhance the robustness of the analysis and interpretation of findings of various research studies.

Triangulation can be used as an effective tool when there are contradictions over the findings derived from the application of a single method. Jakob (2001) argued that "often the purpose of triangulation in specific contexts is 
to obtain confirmation of findings through convergence of different perspectives. The point at which the perspectives converge is seen to represent the reality". Other scholars such as Bruner (2002), Baker et al. (2011), and Dewasiri and Weerakoon (2016) have also strongly recommended triangulation in finance research, but failed to elaborate on specific details and potential implications.

The lack of studies based on empirical mixed methods in finance, the contradictions of the findings of quantitative approaches on financial issues (such as dividend puzzle, capital structure puzzle) and scarcity of theoretical and methodological articles on the triangulation approach in finance research have motivated our study. By addressing the gap in the literature, we comprehensively and critically review and discuss the ways and means of utilizing triangulation in finance research, while at the same time not presenting it as an ultimate or "takeover" approach.

\section{Research Methodology}

The Systematic Literature Review approach has been utilized to review and critically analyze the previous research papers related to the triangulation approach. Figure 1 reflects the strategy adopted for the systematic literature review (SLR). 
Figure 1. The Strategy used for the Systematic Literature Review

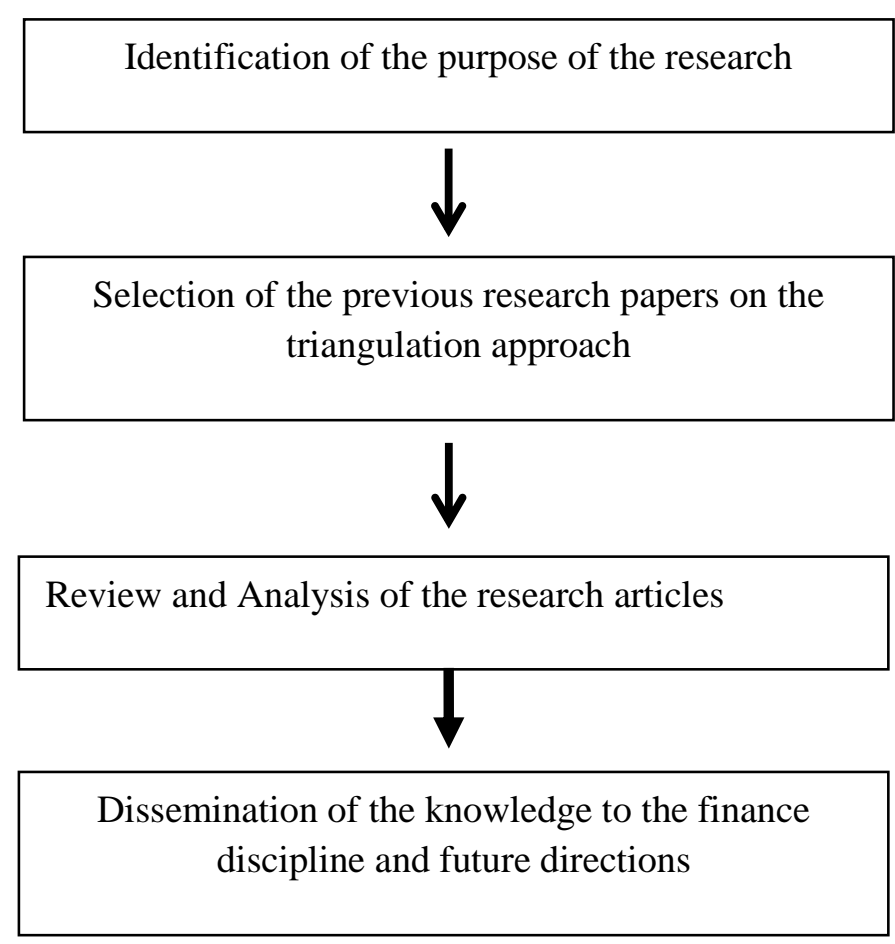

The first step of the SLR involves identification of the relevant key words, time period, and databases for the literature search. Accordingly, the researchers proceeded with the literature search on EMERALD, SAGE, EBSCO, SCIENCE DIRECT, TAYLOR \& FRNACIS, WILLEY, OXFORD, GOOGLE SCHOLAR, and other databases following keywords: triangulation, data triangulation, methodological triangulation, investigator triangulation, theoretical triangulation, mixed method, multi method, along with finance. This study spans a time period around eight decades. The year 1934 is considered as the initial year for data base search since Kelley and Kreys' (1934) study is considered as the earliest application of triangulation approach. Accordingly, the articles published in refereed, peer reviewed journals, full text papers published in English, and articles with the key 
words with its title, abstract, or key words were selected for the literature review. The researchers conducted the database search in April 2018 and included the articles which satisfied the aforementioned criteria and the database search is resultant with 41 research articles $(\mathrm{N}=41)$ for a further review.

\section{The History of Triangulation Approach in Research}

In recent years, the application of multiple methods and approaches to a single phenomenon has received significant attention in social science in general. In fact, there are as many different versions of triangulation as there are articulate proponents of the approach. Even though Kelley and Kreys' (1934) study is the first attempt of triangulation, it is believed that Campbell and Fiskel (1959) laid the foundation of "triangulation" in social science research (Jick,1979) by arguing that more than one trait and method are needed to increase discrimination and convergence of results, proposing what they called a multi trait-multi method matrix. Webb et al. (1966) emphasized the application of unobtrusive (non-reactive) measures instead of interviews, questionnaires and manipulative experiments, in order to avoid their inherent weaknesses. Denzin (1970) identified four forms of triangulation: data triangulation, investigator triangulation, theoretical triangulation and methodological triangulation. Jack and Raturi (2006) emphasized five triangulation approaches, adding multiple triangulation to the list as an approach including multiple observers, theoretical perspectives, sources of data, and methodologies in a single study.

So far, triangulation has been applied in a limited number of studies. Jick (1979) combined qualitative and quantitative approaches and emphasized of the multiple advantages of triangulation; increasing the confidence of 
findings, suggesting new ways to capture research problems, and synthesizing theories applied to the same phenomenon. He demonstrated the use of triangulation by investigating the impact of job insecurity on turnover through multiple methods; surveys, co-worker observations, qualitative interviews, archival sources, and unobtrusive methods. His multiple methods provided consistent and convergent results; however, problems may arise when there are discrepancies across findings. Shih (1998) identified two main reasons for implementing triangulation: completeness and confirmatory purposes. Jack and Raturi (2006) also pointed out that triangulation engenders completeness, confirmation and contingency, and recommended its application to finance research.

In the following, we focus on four triangulation approaches discussed by Denzin (1970), pathways to integration into finance research, benefits, and ways of overcoming potential weaknesses.

\section{Data Triangulation}

Denzin (1970) defined data triangulation as the use of data sources on time, persons and space in a single study. Data sources may vary due to the time of collection, place, and settings (Denzin, 1970; Mitchell, 1986). The study by Kelley and Krey (1934) was one of the earliest applications of data triangulation and relied on two data sources (peer judged by students and the world; association test scores) to test four traits; courtesy, honesty, poise and school drive. There are instances where data are collected concurrently (longitudinal studies) and simultaneously implemented, and therefore cannot be considered under time triangulation. Kimchi et al. (1991) emphasized that studies conducted under time triangulation are based on data collected at different times, and aim is to identify similar findings. Similarly, studies conducted under data triangulation focused on variance in situations, subjects and places with the purpose of increasing the confidence over findings. 
Denzin (1978) and Jick (1979) identified the data triangulation under the "within the method triangulation" approach where two methods in the same tradition are being carried out for complementary and confirmatory purposes. Fielding and Fielding (1986) emphasized that the weaknesses in one data source could be compensated by the strengths of another, which results in increased validity and reliability over findings. Banik (1993) identified the nature and increased amount of data available for interpretation as the main benefits of data triangulation, while Burr (1998) emphasized comprehensiveness and convergence as its main benefits.

\section{How to proceed with data triangulation?}

Turner et al. (2013) presented a single-method investigation of the dividend puzzle (why do companies pay dividends?) through a secondary analysis of financial data. They applied a quantitative methodology and proxies to explain and test current dividend theories. Even though their results were consistent with the signaling hypothesis, they revealed contradictions in the catering theory and prospect theory, and provided little support for the agency and liquidity hypotheses. To solve those inconsistencies, we suggest triangulating the findings from secondary data with primary data (Figure 2). 
Figure 2. Possible application of a data triangulation.
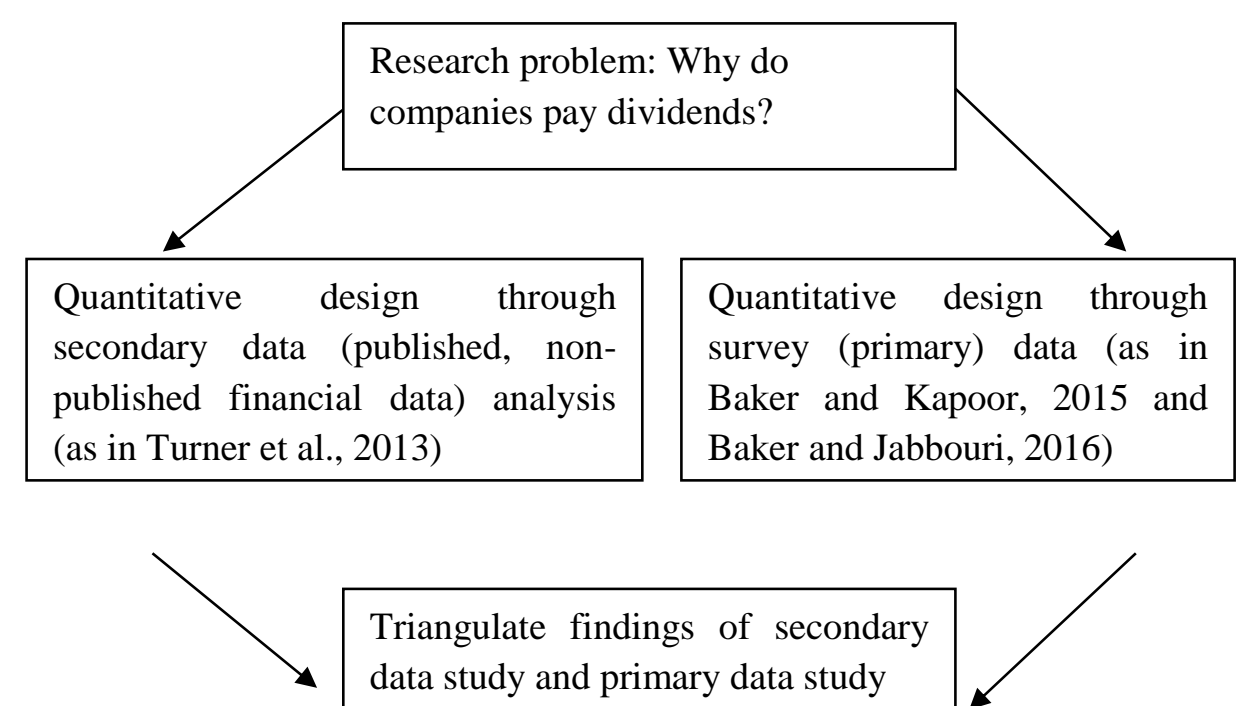

Triangulate findings of secondary data study and primary data study
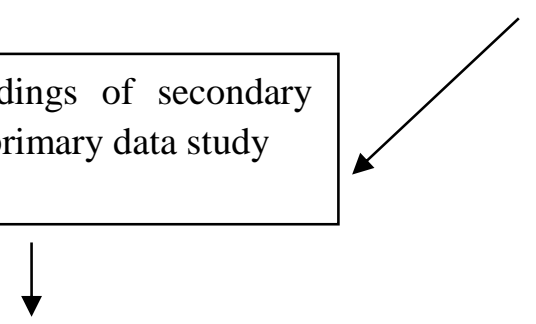

Confirmation over explanations, if inconsistencies occurred, need of further observations or surveys till consensus reached or new explanation emerges.

Source: Authors' own.

It is also possible to observe person variation in the data, and include both investor's and management's views regarding the same phenomenon; this case can also be included in data triangulation. Further, it is conceivable to investigate different contexts (settings) in developed and developing markets. After reviewing all available possibilities, we derived three forms of data triangulation: sequential data triangulation, concurrent data triangulation and multiple data triangulation. 
1. Sequential data triangulation: Data collection and analysis occurs in two phases. One data type or source is followed by another, and interpretation is based on the entire findings.

2. Concurrent data triangulation: Data collection and analysis of two data types occurs concurrently in two phases, minimizing the time required compared to the sequential approach. The preliminary objective of this method is to achieve confirmation while reducing the inherent weaknesses of one data type or source.

3. Multiple data triangulation: More than two data sources to investigate the same phenomenon can be named "multiple data triangulation". It can also be applied to a sequential or concurrent process.

The weaknesses of data triangulation are investigator or respondent biases, difficulties in dealing with big data sets, and the additional cost and time requirements. These weaknesses could be minimized but not easily eliminated. It is possible to classify surveys and interviews where the people under investigation are aware of the experiment. However, situational and personal biasness in the results could still result from other reasons. As Webb et al. (1966) suggested, it is possible to use unobtrusive data sources (archival records like memos, simple observation, videos, recordings) to achieve more comprehensive and complete data triangulation.

\section{Methodological Triangulation}

Campbell and Fiske (1959) laid the foundations of methodological triangulation by identifying the multi-method technique as an important tool to achieve validation and convergence. Denzin (1970) interpreted this approach as "between or across methods triangulation", a view later supported by Jick (1979) and Thurmond (2001). Jick (1979) defined this 
approach as the most popular method of methodological triangulation, as it is based on the use of multiple methodologies (qualitative and quantitative) to investigate a similar phenomenon. The second version of methodological triangulation is known as "within-method triangulation", where multiple data collection is carried out less than one method, thereby achieving higher internal consistency or reliability (Denzin, 1970). The use of the withinmethod is strongly recommended by Jick (1979), since a quantitative method (such as in a survey) allows the acquisition of multiple scales or indices of a single concept. It is thus possible to identify this approach as a type of data triangulation. Within-method triangulation is also identified as a useful cross-validation tool by Onwuegbuzie et al. (2010). In a qualitative study, the within-method is able to combine in-depth interviews and separate observations in the same study. Methodological triangulation also reduces deficiencies and biases which could derive from a single method approach. Additionally, the strengths of one method could compensate for the weaknesses of others.

Unlike other triangulation approaches, methodological triangulation has been applied to management research areas such as marketing, human resources, operations management and business administration, but very rarely to financial studies. The problem often starts at the first step of analysis: namely to choose between to apply the qualitative or quantitative method first, or both concurrently.

Creswell (2009) emphasized four important factors when planning a mixed method procedure; timing, weighting, mixing and theorizing. Timing refers determining when to conduct qualitative and quantitative data collection, and whether to proceed with sequential or concurrent phases. If sequential phases are the preferred choice, the decision whether to proceed firstly with 
qualitative or quantitative study in the research process will depend on the researcher's intention. When qualitative data are collected first, the intention is to explore the phenomenon with a large sample. When data are collected concurrently, implementation should be simultaneous (Creswell, 2009). Weighting refers to whether priority is given to quantitative or qualitative design, which depends on factors such as researcher's interest, audience and purpose of the study. Mixing refers to establishing how to mix data collection and analysis based on multiple methods. According to Creswell (2009), mixing could occur in three phases: connected mixed methods, integrating data and embedding data. In the connected mixed methods, either qualitative or quantitative data collection or analysis occurs first, followed by as is followed by the other approach. In the integrating stage, researchers proceed with qualitative and quantitative data collection concurrently, followed by simultaneous analysis. Under the embedded method, the aim is to collect one type of data, while the other type only provides supporting information. Theorizing (or the "transforming lens") refers to the use of theoretical perspective to guide the entire research study: this entails the operationalization of concepts, the sampling procedure, data collection methods, determining potential implications of the study, among other aspects. Turner et al.'s (2013) exemplifies a study guided by multiple perspectives including signaling theory, catering theory, agency theory, liquidity hypothesis and behavioral explanations. Even though these four factors (timing, weighting, mixing and theorizing) do not exhaust all the possibilities, six major methodological designs were derived from them by Creswell (2009):

1. Sequential Explanatory Design: Quantitative data collection and analysis takes place, followed by qualitative data collection and analysis. Finally, an interpretation of the entire analysis is conducted by the researcher. It 
is useful when researchers show a strong quantitative intention. For instance, Brave et al. (2005) conducted a study through sequential explanatory design to investigate the payout policy. Since the researchers have strong quantitative leaning and unexpected results have arisen within the paradigm, Brave et al. (2005) proceeded with the sequential explanatory design by surveying 384 financial executives followed by 23 qualitative in-depth interviews. The application of mixed methodology is appropriate for their study since the research questions embedded with both qualitative and quantitative aspects (why and what). The drawback of this method is the time involved in the two separate phases, but it contributes to confirmation, completeness and convergence of results.

\section{Figure 3. Possible application of a sequential explanatory strategy}

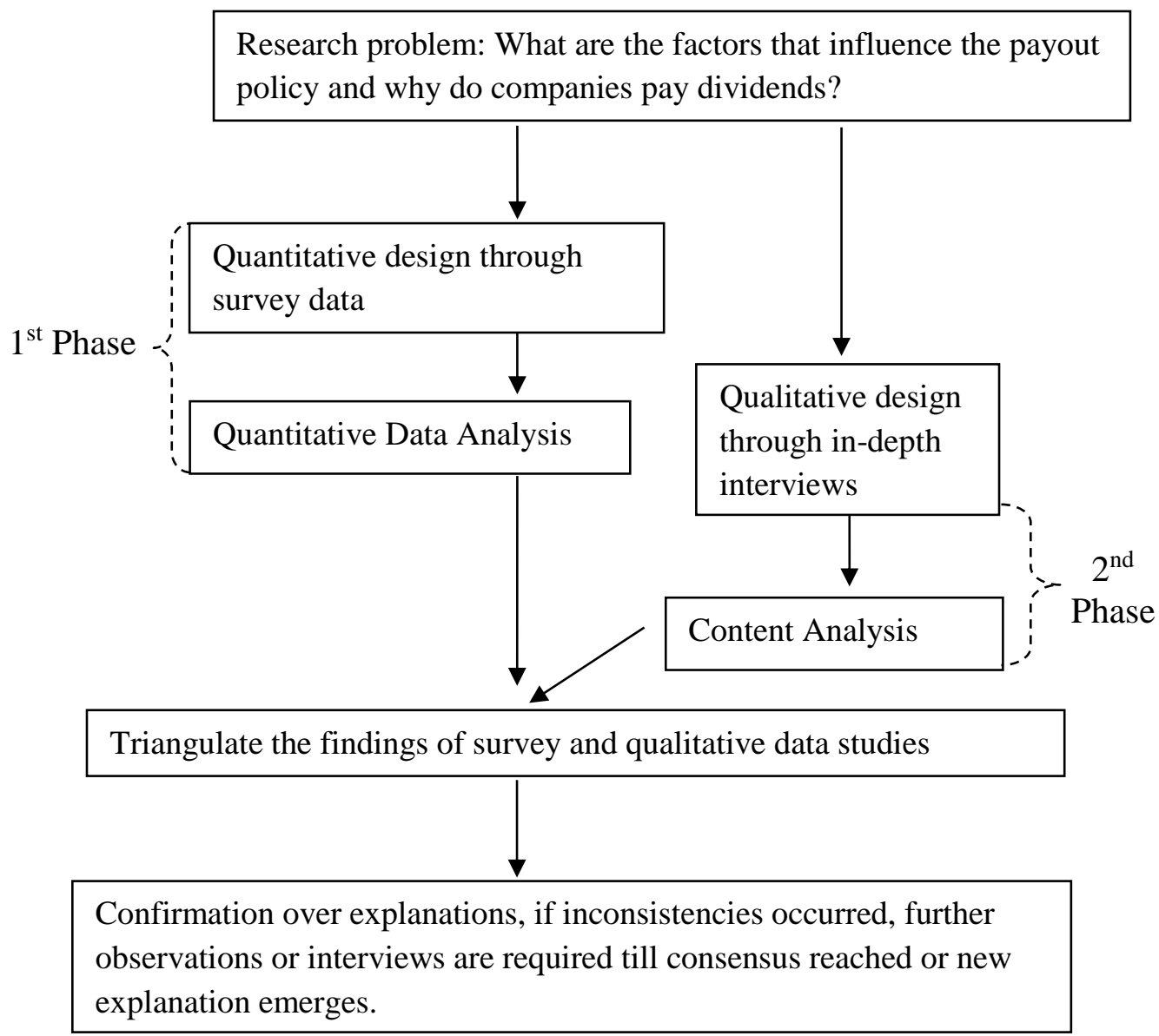

Source: Authors' own. 
2. Sequential Exploratory Design: Qualitative data collection and analysis takes place first, followed by quantitative data collection and analysis, and finally, by an interpretation of the entire results.

Jiraporn et al.'s (2015) study exemplifies this approach. They investigated dividend policy and managerial ability through a quantitative study using proxy variables, and results showed that more talented managers are more likely to pay dividends. Since it is a new investigation in dividend policy which required further validation and confirmation, we suggest that the next step should be to proceed with a qualitative study (interviews) followed by a study of quantitative method (survey), which could provide sound support for a new hypothesis.

3. Sequential Transformative Design: Sequential data collection guided by a strong theoretical backing.

There are numerous theories explaining the dividend puzzle, but Turner et al. (2013) only addressed a limited number such as the information asymmetry, catering, agency, prospect theories and liquidity hypotheses. Their study could have rested on a stronger theoretical framework by amalgamating also the life cycle, free cash flow theories and rent extraction hypotheses, which also attempt to explain the dividend puzzle.

4. Concurrent Triangulation Strategy: In order to achieve analytical convergence, confirmation and corroboration, both quantitative and qualitative data collection and analysis should occur concurrently. 
Creswell (2009) argued that through this strategy the inherent weaknesses of one method could be offset by the other.

Since there is no consensus regarding the best proxy for corporate social performance, and contradicting results in the findings, Soana's (2013) study should be readdressed under the concurrent triangulation strategy. This would require qualitative interviews and field survey concurrently, thereby offset the weaknesses of one method through the other.

5. Concurrent Embedded Strategy: Unlike the concurrent triangulation strategy, the concurrent embedded strategy focusses on a single phase of both qualitative and quantitative data collection. This approach therefore is less time-, effort- and value-consuming that the mixed method. Priority is given to one method based on researcher's primary aims, while the other method plays a supporting role.

An embedded strategy instead of concurrent triangulation results in a supportive role by the qualitative strategy.

6. Concurrent Transformative Strategy: Both quantitative and qualitative data collection occurs at the same time in a single phase, and mixing of evidence occur during the connecting, integrating or embedding stages.

Wang et al. (2016) carried out a study to investigate the catering theory using a proxy variable to explain the investors' demand or preference. Since their study is driven by a theoretical model and further confirmation is required to explain investors preference (behavioral explanation), we recommend the concurrent transformative strategy where the researchers could have data collection at one phase (qualitative interviews of the investors, quantitative survey on 
investors) and mixing data during the connection, integration or embedding stages.

\section{Theoretical Triangulation}

Theoretical triangulation refers to the application of multiple theories or hypotheses concurrently, with the purpose of explaining the same phenomenon (Hopper and Hoque, 2006). The intention is to apply multiple lenses and indicators in conceptualization, to provide sound theoretical support to research design and analysis. Hopper and Hoque (2006) warned that no single theory could enjoy an explanatory monopoly. Lounsbury (2008) argued that researchers tend to use multiple theories to obtain a diversity of actors and practices in their studies. As Hoque et al. (2013) argued, plurality in theory provides complementarity, which adds to the depth and richness of the studied phenomenon. At this point, we emphasize two major paradigms, namely historical sociology and sociological history (Fischer 1995). Rowlinson and Hassard (2013) described historical sociology as historical neo-institutionalism, and sociological history as neoinstitutionalist history. They interpreted historical neo-institutionalism as a 'theory-driven' approach, and neo - institutionalist history as 'story-driven'. Even though researchers in neo-institutionalist history are classified as storydriven (drawing on history to illustrate theory, as is frequently the case with finance researchers), Kieser (1994) proposed that theory could be advanced through the integration of history, as exemplified by the rent extraction hypothesis developed by Shleifer and Vishny (1997) from the free cash flow hypothesis of dividends (Jensen, 1986). Rowlinson and Hassard (2013) argued that neo-institutionalists should focus on applying theory to illuminate history, instead of focusing on historical data to elucidate theory. 
When conducting theoretical triangulation, the major problem is deciding which theoretical perspectives are suitable for the study. There are both competing and complementary theories of a given phenomenon. Regarding the dividend puzzle, there are two major competing theoretical perspectives; dividend relevance and irrelevance. By merely looking at the theoretical assumptions (related to the social reality) and appropriateness, researchers could proceed by combining complementary theories (signalling theory, free cash flow theory, catering theory, agency theory, life cycle theory among others) for confirmation, rejection or modification of the argument. Hoque and Hopper (1997) identified an alternative approach, namely to conduct a pilot study based on different perspectives, and to select the most appropriate theories explaining the research puzzle.

Moreover, Hopper and Hoque (2006) identified two types of theoretical triangulation guiding research. Theories with similar epistemological assumptions are called "within-same tradition", but the problem arises with "out of the tradition" arguments. Hoque et al. (2013) argued that the core assumptions regarding ontology, epistemology and human nature provide-the rationale for the particular ways of implementing theoretical triangulation in practise. They argued that proper justifications are required when selecting multiple theories, and that they are particularly useful when researchers hold multi-layers of insights on the phenomenon. Finally, we emphasize the four interrelated selection criteria of theories in triangulation introduced by Covaleski et al. (2003) for deciding between competing and compatible explanations. First, variable names and meanings should be in line with the theories; second, explanations of causal process with different perspectives should be consistent; third different theoretical perspectives should be based on the same unit of analysis ( individual or firm level); and fourth theories should entail causal-model forms. Furthermore, if researchers proceed with 
multiple sources of data (data triangulation), they are able increase the accuracy of their judgments and will be closer to attaining consensus over explanations.

\section{Investigator Triangulation}

Thurmond (2001) described investigator triangulation as a type of triangulation which requires more than one observer, interviewer, investigator or data analyst whose primary responsibility is to collect and interpret data without prior discussion with others. Eventually the findings are amalgamated based on the consensus amongst the investigators. Denzin (1970) argued that this approach provides greater credibility to observations while increasing trust over findings. The benefits of investigator triangulation are: establishing cross-investigator confirmation, minimizing intrinsic biases of investigators, strengthening validity and reliability, and ultimately increasing the robustness of findings. It is important to notice that reduction in bias may sometimes undermine the objectivity of findings, as it may be caused by a resistance to new or unknown facts. It is thus suggested to match investigator triangulation to one or more alternative triangulation methods, and to allocate experts on qualitative and quantitative methods as investigators. Hence, it is possible to conduct any kind of triangulation study (data or methodology) by selecting two or more experts on qualitative and quantitative methods as investigators, thereby overcoming the gaps arisen from a single method. When multiple triangulation methods are used in a single study, it is known as "multiple triangulation".

\section{How to proceed with data analysis in a triangulated research?}

Researchers should revise their conceptual framework to include data, investigator, methodological or multiple triangulation, and thereby achieve outcome higher level of theoretical pluralism. Each question or objective in a 
study should be investigated with the aim of achieving confirmation and comprehension of the findings of each strategy (Thurmond, 2001). The seminal study by Dunning et al. (2008) was based on a mixed method approach to quality of life (QoL) and rested on a different philosophical paradigm (geography). They employed a sound methodological approach combining face to face qualitative interviews and a quantitative survey. They properly proceeded with confirmation and comprehension procedures according to stated research questions and objectives.

Confirmation is defined as the convergence of two data sets based on the operationalization of two available approaches. Even though researchers use various statistical tools for confirmation of findings derived from two methodological approaches, problems have arisen when quantifying qualitative data, such as single case findings (outliers), or a non-existing or non-identified code (Thurmond, 2001). In order to avoid such difficulties, Mitchell (1986) introduced "conceptual validation" as an alternative approach whereby logical patterns of relationships among variables are investigated in both quantitative and qualitative methods. Then revised hypotheses are generated and tested in order to overcome gaps derived from the mixed methodology. Mixing of qualitative and quantitative findings leads to increased comprehension, which accelerates the understanding of the phenomenon (Morse, 2003).

The difference between confirmation and comprehension is demonstrated by Mitchell (1986) as shown in Figure 4. 
Figure 4. Confirmation and Comprehension.

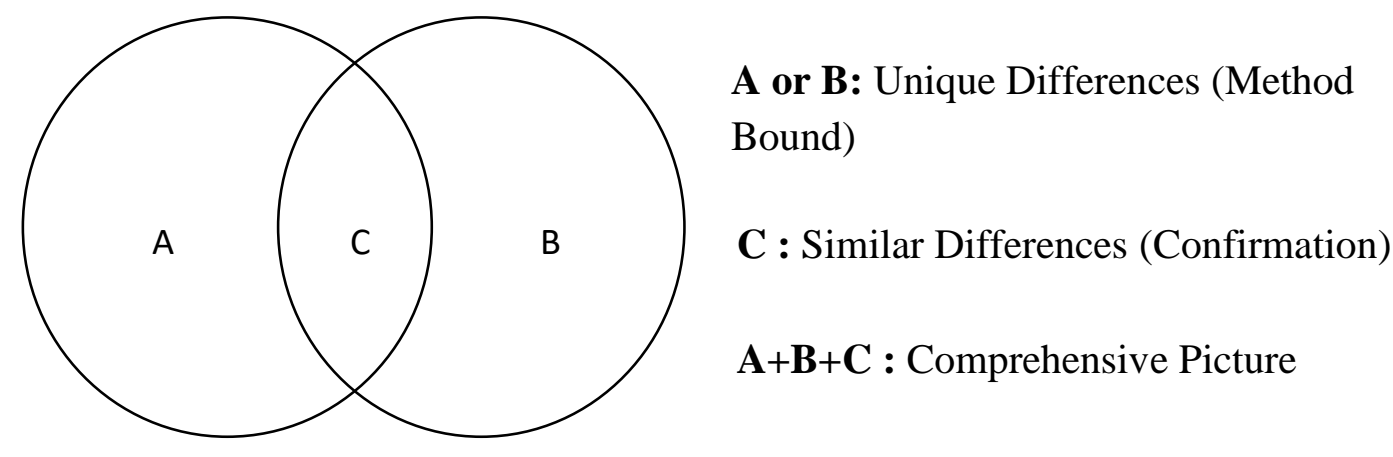

Source: Adapted from Mitchell (1986).

Even though confirmation refers to similarities of findings (or similar differences), comprehension refers to the total findings (which also include unique differences). If there are unique differences in findings, the two methodologies must be revised in terms of the dimension and indicator level characterizing the whole research process, including wording, coding and conceptual validation. Mitchell (1986) observed that confirmation and comprehension of concepts are not mutually exclusive, which corroborates Dunning et al. (2008) observations. Sometimes, the lack of confirmation may lead to increased insights on the phenomenon, which would not have been achieved from a single method (Dunning et al., 2008)

\section{Conclusion and Practical Implications}

In this study, the ways and means of applying triangulation approaches in finance research have been comprehensively and critically reviewed. In addition, we highlighted its benefits, modes of reducing weaknesses, and importance of congruence, completeness and divergence. As a concluding remark, we argue that applying triangulation may promote a consensus on prevailing issues in financial phenomena that remain after decades (such as the capital structure puzzle). Moreover, we suggest that finance researchers 
should justify their selection of relevant methodology, eliminate convenient methodology selection biases, and minimize the inherent weaknesses of the selected methodology.

In summary, it is possible to apply the triangulation approach to finance research in five ways: data triangulation, methodological triangulation, theoretical triangulation, investigator triangulation and multiple triangulation. Despite numerous challenges and issues faced by researchers, it is possible to propose a creation of a new hybrid discipline in finance research merging incongruent binaries within the same tradition. This new discipline would contribute to reducing the quantitative-qualitative methodological divide, while bridging the gaps between dissimilar areas in finance.

\section{References}

Baker, H.K., Singleton,J.C. \& Veit, E.T. (2011) Survey Research in Corporate Finance Bridging the Gap between Theory and Practice. New York: Oxford University Press.

Baker,H.K. and Jabbouri, I. (2016) How Moroccan managers view dividend policy, Managerial Finance, 42(3), 270-288.

Baker, H.K. and Kapoor, S. (2015) Dividend policy in India: new survey evidence, Managerial Finance, 41(2), 182 - 204.

Banik, B.J. (1993) Applying triangulation in nursing research. Applied Nursing Research, $6(1), 47-52$.

Brav, A., Graham, J. R., Harvey, C. R. \& Michaely, R. (2005) Payout policy in the 21st century. Journal of Financial Economics, 77, 483-527.

Bruner, R.F. (2002) Does M \&A pay? A survey of evidence from the decision-maker. Journal of Applied Finance, 12(1), 48-68. 
Burr, G. (1998) Contextualizing critical care family needs through triangulation: An Australian study. Intensive \& Critical Care Nursing, 14(4), 161-169.

Burton, B. (2007) Qualitative research in finance - pedigree and renaissance. Studies in Economics and Finance, 24(1), 5-12.

Campbell, D. \& Fiske, D. (1959) Convergent and Discriminant Validation by the MultitraitMulti method Matrix. Psychological Bulletin, 56(2), 81-105.

Covaleski, M.A., Evans, J.H. III, Luft, J.L. \& Sheilds, M.D. (2003) Budgeting research: three theoretical perspectives and criteria for selective integration. Journal of Management Accounting Research, 15, 3-49.

Creswell, J. W. (2009) Research design: qualitative, quantitative, and mixed methods approaches. London, England: Sage.

Decrop, A. (1999) Triangulation in qualitative tourism research. Amsterdam, Netherland: Elsevier.

Denzin, N. K. (1970) Sociological Methods: A Sourcebook. New Brunswick, Canada: Transaction Publishers.

Denzin, N. K. (1978) The Research Act, New York: McGraw-Hill.

Dewasiri, N. J. \& Weerakoon, .Y. K. B. (2016) Why Do Companies Pay Dividends?: A Comment. Journal of Corporate Ownership and Control, 13(2), 443-453.

Dunning, H., Williams, A., Abonyi, S. \& Crooks, V. (2008) Mixed Method Approach to Quality of Life Research: A Case Study Approach. Social Indicators Research, 85(1), 145158.

Fielding, N.G., \& Fielding, J.L. (1986) Linking data. Beverly Hills, California: Sage.

Fischer, C. S. 1995. Historical Sociology and Sociological History: Theory and Practice. Florence, Italy: European University Institute. 
Frankfurter, G., Kosedag, A., Schmidt, H. \& Topalov, M. (2001) The perception of dividends by management. Journal of Psychology and Financial Markets, 3, 202-217.

Greene, J. (2007) Mixed methods in social inquiry. San Francisco, California: Wiley.

Hopper, T. \& Hoque, Z. (2006) Triangulation approaches to accounting research. In Hoque, Z. (Ed.), Methodological Issues in Accounting Research: Theories and Methods (pp. 477486).London, England: Spiramus.

Hoque, Z., Covaleski, M.A. \& Gooneratne, T.N. (2013) Theoretical triangulation and pluralism in research methods in organizational and accounting research. Accounting, Auditing \& Accountability Journal, 26(7), 1170-1198.

Hoque, Z. \& Hopper, T. (1997) Political and industrial relations turbulence, competition \& Budgeting in the nationalized jute mills of Bangladesh. Accounting and Business Research, 27(2), 125-143.

Jack, E.P. \& Raturi, A.S. (2006) Lessons learned from methodological triangulation in management research. Management Research News, 29(6), 345-357.

Jakob, A. (2001) On the Triangulation of Quantitative and Qualitative Data in Typological Social Research: Reflections on a Typology of Conceptualizing 'Uncertainty' in the Context of Employment Biographies. Qualitative Social Research Forum, 2(1), 1-29.

Jensen, M.C. (1986) Agency costs of free cash flow, corporate finance, and takeovers. American Economic Review, 76(1), 323-329.

Jick, T.D. (1979) Mixing qualitative and quantitative methods: triangulation in action. Administrative Science Quarterly, 24(4), 602-611.

Jiraporn, P., Leelalai, V. \& Tong, S. (2015) The effect of managerial ability on dividend policy: how do talented managers view dividend payouts? Applied Economics Letters, 23(12), 857-862. 
Kelley, T. L. \& Krey, A. C. (1934) Tests and measurements in the social sciences. New York: Scribner.

Kieser, A. (1994) Crossroads - Why Organization Theory Needs Historical Analyses - And How These Should be Performed. Organization Science, 5(4), 608-620.

Kimchi, J., Polivka, B., \& Stevenson, J.S. (1991) Triangulation: Operational definitions. Nursing Research, 40(6), 364-366.

Lintner, J. (1956) Distribution of incomes of corporations among dividends, retained earnings and taxes. American Economic Review, 46(2), 97-113.

Lounsbury, M. (2008) Institutional rationality and practice variation: new directions in the institutional analysis of practice. Accounting, Organizations and Society, 33, 349-361.

Mitchell, E.S. (1986) Multiple triangulation: A methodology for nursing science. Advances in Nursing Science, 8(3), 18-26.

Morse, J. M. (2003) Principles of mixed methods and multi-method research design. In A. Tashakkori \& C. Teddlie (Ed.), Handbook of mixed methods in social and behavioral research (pp. 189-208). Thousand Oaks: Sage.

Onwuegbuzie, A. J., Bustamante, R. B. \& Nelson, J. A. (2010) Mixed research as a tool for developing quantitative instruments. Journal of Mixed Methods Research, 4, 56-78.

Rowlinson, M. \& Hassard, J.S. (2013) Historical neo-institutionalism or neo-institutionalist history? Historical research in management and organization studies. Management \& Organizational History, 8(2), 111-126.

Shih, F. (1998) Triangulation in Nursing Research: Issues of Conceptual Clarity and Purpose. Journal of Advanced Nursing, 28(3), 631-641.

Shleifer, A. \& Vishny, R. (1997) A survey of corporate governance. Journal of Finance, 52(1), 737-783.

Soana, M. (2011) The Relationship between Corporate Social Performance and Corporate Financial Performance in the Banking Sector. Journal of Business Ethics, 104(1), 133-148. 
Thurmond, V. A. (2001) The point of triangulation. Journal of Nursing Scholarship, 33(1), 253-258.

Turner, J.D., Ye, Q. \& Zhan, W. (2013) Why do companies pay dividends: Evidence from an early and unregulated capital market. Review of Finance, 17, 1787-1826.

Wang, M, Ke, M., Lin, F. \& Huang, Y. (2016) Dividend policy and the catering theory: evidence from the Taiwan Stock Exchange. Managerial Finance, 42(10), 999-1016.

Webb, E. J., Campbell, D. T., Schwartz, R. D. \& Sechrest, L. (1966) Unobtrusive Measures: Nonreactive Research in the Social Sciences. Chicago, IL: Rand McNally. 